\title{
Isolation and characterisation of Shiga toxigenic Escherichia coli strains from northern Palestine
}

\author{
K. ADWAN, N. ABU-HASAN, T. ESSAWI* and M. BDIR \\ Department of Biological Sciences, An-Najah N. University and *Department of Biological Sciences, Bir Zeit \\ University, Palestine
}

\begin{abstract}
Shiga toxigenic Escherichia coli (STEC) isolates from symptomatic and asymptomatic patients in northern Palestine in 1999 were screened for serotype 0157 and characterised for virulence genes by multiplex PCR assay. Of the 176 STEC isolates, $124(\mathbf{7 0 . 5 \%})$ were of serotype 0157. All these isolates carried the gene for Shiga toxin type $1\left(s t x_{1}\right)$ and $112(90.3 \%)$ carried st $x_{2}$. The intimin encoding gene locus eae was detected in 16 isolates $(12.9 \%)$ and the enterohaemolysin encoding gene, hly $A$, in 18 (14.5\%). Statistical analysis showed a significant association between the presence of $e a e A$ and $h l y A$, either alone or combined with $s t x_{1}$ and $s t x_{2}$ genes in 0157 isolates from symptomatic infection. ERIC-PCR analysis of DNA from 80 serotype 0157 isolates revealed three major clonal populations.
\end{abstract}

\section{Introduction}

Shiga toxigenic Escherichia coli (STEC) are an important cause of gastrointestinal disease in man. Infection with these organisms may result in lifethreatening complications such as haemolytic-uraemic syndrome (HUS) and thrombotic thrombocytopenic purpura $[1,2]$. Within the STEC family, certain strains, such as those of serotype $\mathrm{O} 157$ or those that have particular combinations of putative virulence factors, appear to be more virulent for man [1-3]. Numerous outbreaks of STEC-related disease have been attributed to serotype $\mathrm{O} 157$, although the latter accounts for only c. $60 \%$ of isolates in outbreaks [4]. Indeed, several strains of other serotypes have been implicated in both sporadic infections and outbreaks caused by STEC. In some studies, non-O157 strains have represented $20 \%$ [5] and 30\% [6] of STEC isolated.

Several virulence factors have been described in STEC, including Shiga toxin type 1 (Stx1, encoded by $s t x_{1}$ ), Shiga toxin type $2\left(\operatorname{Stx} 2, s t x_{2}\right)$, intimin (eaeA) and the plasmid-borne enterohaemolysin encoded by enterohaemorrhagic E. coli (EHEC) hlyA [2,7-9]. The present study was initiated to assess the importance of STEC as an aetiological agent of acute diarrhoea among Palestinians. The presence of $s t x_{1}, s t x_{2}, e a e A, h l y A$ and

Received 16 May 2001; revised version received 12 Nov. 2001; accepted 21 Nov. 2001.

Corresponding author: Dr K. Adwan (e-mail: adwan@ najah.edu).
O157 rfbE genes was tested for simultaneously by a multiplex PCR [2] and the clonal structure of the population of isolates was examined by genomic DNA fingerprinting by enterobacterial repetitive intergenic concensus-PCR (ERIC-PCR) [10].

\section{Materials and methods}

\section{STEC isolates}

A total of 250 stool samples was collected during an outbreak of diarrhoea between February and June 1999 in the north of Palestine. Samples were obtained from symptomatic patients, i.e., those with diarrhoea with or without blood or with clinical signs of HUS, and asymptomatic patients. Samples were plated on MacConkey agar, incubated overnight at $37^{\circ} \mathrm{C}$, and a loopful of growth from the first inoculation streak was suspended in $0.5 \mathrm{ml}$ of distilled water and boiled for $10 \mathrm{~min}$. After centrifugation of the lysate, the supernate was used in PCR.

\section{Multiplex PCR}

The $s t x_{1}, \quad s t x_{2}$, eaeA, hlyA and $0157 \quad r f b E$ gene sequences were detected with the primer pairs described previously [2]. Details of the nucleotide sequence, the specific gene region amplified and the size of the PCR product for each primer pair are given in Table 1. Samples $(5 \mu \mathrm{l})$ of each extract were amplified in $50-\mu 1$ reaction mixtures with 35 PCR cycles each consisting of $1 \mathrm{~min}$ of denaturation at 
Table 1. Primers used in multiplex PCR

\begin{tabular}{|c|c|c|c|}
\hline Primer & Sequence $\left(5^{\prime}-3^{\prime}\right)$ & Specificity & $\begin{array}{c}\text { Amplicon } \\
\text { size (bp) }\end{array}$ \\
\hline stx1F & ATAAATCGCCATTCGTTGACTAC & nt $454-633$ of A subunit coding region of $s t x_{1}$ & 180 \\
\hline stx1R & AGAACGCCCACTGAGATCATC & & \\
\hline stx $2 \mathrm{~F}$ & GGCACTGTCTGAAACTGCTCC & nt $603-857$ of A subunit coding region of $s t x_{2}$ (including $s t x_{2}$ variants) & 255 \\
\hline stx2R & TCGCCAGTTATCTGACATTCTG & & \\
\hline eaeAF & GACCCGGCACAAGCATAAGC & nt $27-410$ of eaeA (this region is conserved between EPEC and STEC) & 384 \\
\hline eaeAR & CCACCTGCAGCAACAAGAGG & & \\
\hline hlyAF & GCATCATCAAGCGTACGTTCC & nt $70-603$ of EHEC hlyA & 534 \\
\hline hlyAR & AATGAGCCAAGCTGGTTAAGCT & & \\
\hline $\mathrm{O} 157 \mathrm{~F}$ & CGGACATCCATGTGATATGG & nt $393-651$ of $r f b E_{\mathrm{O} 157: \mathrm{H} 7}$ & 259 \\
\hline O157R & TTGCCTATGTACAGCTAATCC & & \\
\hline
\end{tabular}

nt, nucleotide; EPEC, enteropathogenic E. coli.

$95^{\circ} \mathrm{C}, 2 \mathrm{~min}$ of annealing at $65^{\circ} \mathrm{C}$ for the first 10 cycles, decreasing to $60^{\circ} \mathrm{C}$ by cycle 15 with elongation for $1.5 \mathrm{~min}$ at $72^{\circ} \mathrm{C}$, rising to $2.5 \mathrm{~min}$ from cycles 25 to 35 . PCR products were separated by electrophoresis in agarose $2 \%$ gels and stained with ethidium bromide. Strains ATCC 43890 and ATCC 43894 were used as positive control strains for $s t x_{1}$ and $s t x_{2}$ respectively. Distilled water served as a negative control.

At least $10 \mathrm{E}$. coli-like colonies from primary plate PCR-positive cultures were retested by the same PCR protocol. Isolates were confirmed as E. coli by the API 20 E system (bioMérieux, Marcy L'Etoile, France) and tested for sorbitol fermentation on sorbitol MacConkey agar (SMAC). The $\mathrm{O} 157$ antigen of isolates was confirmed by agglutination with a specific latex reagent (Oxoid).

\section{$E R I C-P C R$}

PCR was performed with primer ERIC2, 5'AAGTAAGTGAC TGGGGT GAGCG3' [10] and crude heated isolates in $25-\mu 1$ reaction mixtures with $5 \mu$ l of template DNA. Initial denaturation was at $94^{\circ} \mathrm{C}$ for 5 min followed by 40 cycles of amplification (denaturation at $94^{\circ} \mathrm{C}$ for $60 \mathrm{~s}$, annealing at $25^{\circ} \mathrm{C}$ for $60 \mathrm{~s}$ and extension at $72^{\circ} \mathrm{C}$ for $90 \mathrm{~s}$ ) ending with a final extension at $72^{\circ} \mathrm{C}$ for $5 \mathrm{~min}$. Separated PCR products in agarose gels were visualised as above and patterns that differed by one or more DNA bands were considered to be different ERIC-types.

\section{Antimicrobial susceptibility}

The susceptibility of isolates to antimicrobial agents was determined by disk diffusion [11] in accordance with National Committee for Clinical Laboratory Standards [12]. The following antibiotics $(\mu \mathrm{g})$ were used: gentamicin (10), norfloxacin (10), imipenem (10), ampicillin (10), tazobactam (100), amikacin (30) and piperacillin (100).

\section{Statistical analysis}

Significant differences were calculated by the $\chi^{2}$ test and statistical significance was defined as $\mathrm{p}<0.05$.

\section{Results}

STEC was identified in $176(70.4 \%)$ of 250 stool samples. Of the 176 STEC isolates, 120 were from symptomatic and 56 from asymptomatic patients. Abdominal pain was reported by 59 patients $(33.5 \%)$ and a temperature of $>38^{\circ} \mathrm{C}$ in $30(17.1 \%)$. One hundred and twenty-four $(70.5 \%)$ of the STEC isolates were sorbitol negative and of serotype O157. All the O157 isolates were positive for $s t x_{1}$ and $112(90.3 \%)$ for $\mathrm{s} t x_{2} ;$ eae was detected in $16(12.9 \%)$ and hlyA in 18 (14.5\%). Among the 52 non-O157 isolates, 28 carried $s t x_{1}$ or $s t x_{2}$, or both, and 24 had $s t x_{1}$ alone (Table 2). The distribution of genes in the $\mathrm{O} 157$ isolates from symptomatic and asymptomatic patients showed no evidence $(\mathrm{p}>0.05)$ to support an association between $s t x_{1}$ and $s t x_{2}$, or $s t x_{1}$ alone, and the pathogenic potential

Table 2. Distribution of genes encoding virulence factors in 176 STEC isolates and ERIC-PCR patterns of 80 STEC isolates from symptomatic and asymptomatic patients

\begin{tabular}{|c|c|c|c|c|c|c|c|c|}
\hline \multicolumn{5}{|c|}{ STEC genotype } & \multirow[b]{2}{*}{ Serogroup } & \multicolumn{2}{|c|}{ Number of isolates from } & \multirow{2}{*}{$\begin{array}{c}\text { ERIC-PCR } \\
\text { pattern (number of isolates) }\end{array}$} \\
\hline$s t x_{1}$ & $s t x_{2}$ & eaeA & hlyA & Total & & symptomatic & asymptomatic & \\
\hline+ & + & + & - & 5 & O157 & 4 & 1 & $\ldots$ \\
\hline+ & + & - & + & 7 & O157 & 6 & 1 & E5 (1) \\
\hline+ & + & - & - & 89 & O157 & 55 & 34 & E1 (42), E2 (1), E4 (17) \\
\hline+ & - & - & - & 12 & O157 & 7 & 5 & E2 (10) \\
\hline+ & + & - & - & 28 & Non-O157 & 19 & 9 & $\ldots$ \\
\hline+ & - & - & - & 24 & Non-O157 & 19 & 5 & $\ldots$ \\
\hline
\end{tabular}

+ , gene present; -, gene absent. 


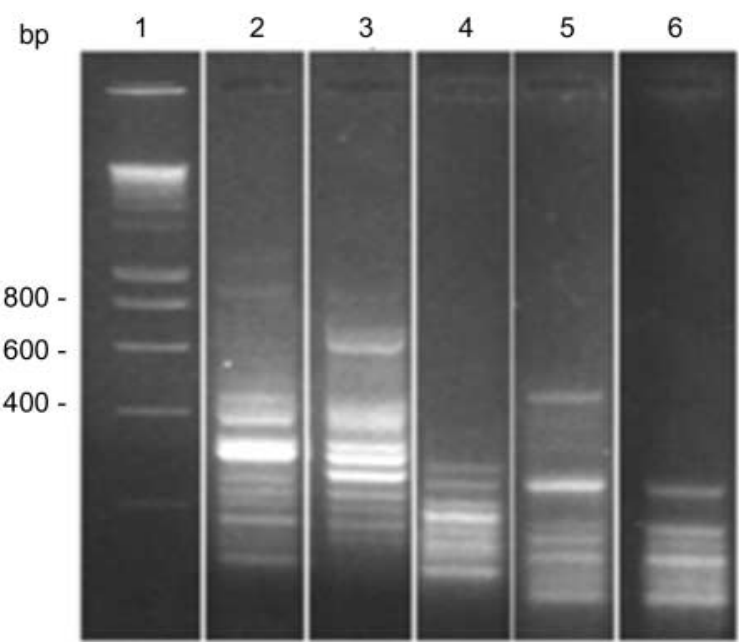

Fig. 1. Representative ERIC-PCR profiles of DNA from STEC isolates. Lane 1, molecular sizes marker (100-bp ladder DNA); 2, pattern E1; 3, E2; 4, E3; 5, E4; 6, E5.

of the isolate (Table 2). Stx $x_{1}$ alone and $s t x_{1}$ plus $s t x_{2}$ were present, respectively, in similar proportions of O157 isolates from symptomatic patients $(100 \%$, $91.5 \%)$ and asymptomatic patients $(100 \%, 88.1 \%)$. However, eaeA- and hlyA-encoding genes were significantly more frequent in isolates from symptomatic cases $(17.1 \%$ and $19.5 \%$, respectively) $(\mathrm{p}<0.05$ for each) than from asymptomatic cases (4.8\% each). A strong association was found between the combination of $s t x_{1}, s t x_{2}, e a e A$ and hylA genes and the patient source of $\mathrm{O} 157$ isolates $(\mathrm{p}<0.05)$.

ERIC-PCR analysis of 80 isolates of serotype 0157 revealed five distinct DNA patterns, E1-E5 (Fig. 1). Patterns E1, E2 and E4 were represented by 42 (52.5\%), $11(13.8 \%)$ and $17(21.3 \%)$ isolates, respectively; pattern E3 was restricted to 4 isolates and E5 to 6 isolates (Table 2). Repeat testing of five isolates by ERIC-PCR 2 months apart showed that the DNA patterns were stable and reproducible.

Of the seven antimicrobial agents tested, resistance to ampicillin and tazobactam was present in $83 \%$ of STEC isolates with resistance to piperacillin in $81 \%$, norfloxacin $59 \%$, gentamicin $55.1 \%$, amikacin $48 \%$ and imipenem $26 \%$. Resistance to five or more drugs was found in $49 \%$ of the isolates.

\section{Discussion}

STEC, especially those of serotype O157, are increasingly isolated from severe diarrhoeal disease and constitute a serious medical problem for many patients $[1,3]$. This study is the first to address the prevalence of STEC in stool samples from the northern part of Palestine where poor hygienic conditions are common; $70.4 \%$ of stool samples were positive for STEC and $70.5 \%$ of these isolates were serotype 0157 .
These results are consistent with data from Finland [5] which showed $\mathrm{O} 157$ to be the major STEC serogroup. Although strains of $\mathrm{O} 157$ predominated, the proportion of non-O157 isolates (29.5\%) among STEC in Palestine is similar to reported frequencies in Finland (20\%) and Belgium $(30 \%)[5,6]$. The $s t x_{1}$ and $s t x_{2}$ genes were very frequent among $\mathrm{O} 157$ isolates from Palestine but there was a low frequency of $h l y A$ and eaeA. To our knowledge, $\mathrm{O} 157$ isolates with these characteristics are rare globally. In many studies, isolates with a genetic profile of eaeA, hlyA and $s t x_{1}$, either alone or combined with $s t x_{2}$ have been the most prevalent $[5,13,14]$. However, strains similar in genetic profile to those described here have been reported to occur sporadically [14]. The frequency of serotype $\mathrm{O} 157$ isolates with this complement of genes might be explained by the expansion of three major clones, defined by ERICPCR analysis, which together accounted for $87.5 \%$ of the isolates.

A relationship between the virulence factors carried or expressed by $\mathrm{O} 157$ isolates and their pathogenic potential for man has been proposed. Strains producing Stx2 appear to be more virulent for man than those producing only Stx $1[3,5,15,16]$. This view is not supported by the toxigenic profiles of $\mathrm{O} 157$ isolates from Palestinian patients. Here, O157 isolates typically carried $s t x_{1}$, either alone or with $s t x_{2}$. However, a significant association was observed between both hly $A$ and eaeA, either independently or with $s t x_{1}$ and $s t x_{2}$ genes and the patient source of O157. These results confirm the observations of a previous study [3] and support the suggestion of synergy between the adhesin intimin, enterohaemolysin and Shiga toxin.

The antimicrobial susceptibility patterns of the STEC isolates are a cause for concern as almost half were resistant to five or more agents. Similar rates of resistance have been reported [5]. The high rate in northern Palestine may be due, in part, to selective pressure resulting from uncontrolled use of broadspectrum antibiotics compounded by a lack of antibiotic prescribing policy and the sale of antibiotics over-the-counter to the general public.

\section{References}

1. Paton JC, Paton AW. Pathogenesis and diagnosis of Shiga toxin-producing Escherichia coli infections. Clin Microbiol Rev 1998; 11: 450-479.

2. Paton AW, Paton JC. Detection and characterization of shiga toxigenic Escherichia coli by using multiplex PCR assays for $s t x_{1}$, st $x_{2}$, eaeA, enterohemorrhagic $E$. coli hlyA, rfb $b_{\mathrm{O} 111}$, and $r f b_{\mathrm{O} 157}$. J Clin Microbiol 1998; 36: 598-602.

3. Boerlin P, McEwen SA, Boerlin-Petzold F, Wilson JB, Johnson RP, Gyles CL. Association between virulence factors of Shiga toxin-producing Escherichia coli and disease in humans. J Clin Microbiol 1999; 37: 497-503.

4. Goldwater PN, Bettelheim KA. New perspectives on the role of Escherichia coli O157:H7 and other enterohaemorrhagic E. coli serotypes in human disease. J Med Microbiol 1997; 47: 1039-1045.

5. Keskimäki M, Saari M, Heiskanen T, Siitonen A. Shiga toxin- 
producing Escherichia coli in Finland from 1990 through 1997: prevalence and characteristics of isolates. $J$ Clin Microbiol 1998; 36: 3641-3646.

6. Piérard D, Van Etterijck R, Breynaert J, Moriau L, Lauwers S. Results of screening for verocytotoxin-producing Escherichia coli in faeces in Belgium. Eur J Clin Microbiol Infect Dis 1990; 9: 198-201.

7. Advisory Committee on the Microbiological Safety of Food. Report on verocytotoxin-producing Escherichia coli. London, HMSO. 1995.

8. Beutin L, Montenegro MA, Ørskov I et al. Close association of verotoxin (shiga-like toxin) production with enterohemolysin production in strains of Escherichia coli. J Clin Microbiol 1989; 27: 2559-2564.

9. World Health Organization. Consultation on the prevention and control of enterohaemorrhagic Escherichia coli. Geneva, World Health Organization. 1997: 39.

10. Dalla-Costa LM, Irino K, Rodrigues J, Rivera ING, Trabulsi LR. Characterization of diarrhoeagenic Escherichia coli clones by ribotyping and ERIC-PCR. J Med Microbiol 1998; 47: 227-234.

11. Bauer AW, Kirby WMM, Sherris JC,Turck M. Antibiotic susceptibility testing by a standardized single disk method. $\mathrm{Am}$ $J$ Clin Pathol 1966; 45: 493-496.
12. National Committee for Clinical Laboratory Standards. Performance standards for antimicrobial disc susceptibility tests: tentative standards, vol. 3, no. 24, NCCLS document M2-A5. Villanova, PA, National Committee for Clinical Laboratory Standards. 1993.

13. Heuvelink AE, van de Kar NCAJ, Meis JFGM, Monnens LAH, Melchers WJG. Characterization of verocytotoxin-producing Escherichia coli $\mathrm{O} 157$ isolates from patients with haemolytic uraemic syndrome in Western Europe. Epidemiol Infect 1995; 115: $1-14$

14. Rios M, Prado V, Thucksis M et al. Clonal diversity of Chilean isolates of enterohemorrhagic Escherichia coli from patients with hemolytic-uremic syndrome, asymptomatic subjects, animal reservoirs, and food products. J Clin Microbiol 1999; 37: $778-781$.

15. Ostroff SM, Tarr PI, Neill MA, Lewis JH, Hargrett-Bean N, Kobayashi JM. Toxin genotypes and plasmid profiles as determinants of systemic sequelae in Escherichia coli O157:H7 infections. J Infect Dis 1989; 160: 994-998.

16. Karpman D, Connell H, Svensson M, Scheutz F, Alm P, Svanborg C. The role of lipopolysaccharide and shiga-like toxin in a mouse model of Escherichia coli $\mathrm{O} 157: \mathrm{H} 7$ infection. $J$ Infect Dis 1997; 75: 611-620. 